American Journal of Applied Sciences 9 (3): 436-439, 2012

ISSN 1546-9239

(C) 2012 Science Publications

\title{
Heat Transfer Augmentation for Electronic Cooling
}

\author{
Suabsakul Gururatana \\ Mechanical Engineering Program, Faculty of Engineering at Si Racha, \\ Kasetsart University Si Racha Campus, Chonburi, 20230 Thailand
}

\begin{abstract}
Problem statement: The performance of electronic devices has been improving along with the rapid technology development. Cooling of electronic systems is consequently essential in controlling the component temperature and avoiding any hot spot. The study aims to review the present electronic cooling methods which are widely used in electronic devices. Approach: There are several methods to cool down the electronics components such as the pin-fin heat sink, confined jet impingement, heat pipe, micro heat sink and so on. Results: The cooling techniques can obviously increase heat transfer rate. Nonetheless, for active and passive cooling methods the pressure drop could extremely rise, when the heat transfer rate is increased. Conclusion: When the cooling techniques are used, it is clearly seen that the heat transfer increases with pressure drop. To avoid excessive expense due to high pressure drop, optimization method is required to obtain optimum cost and cooling rate.
\end{abstract}

Key words: Rapid development, electronics components, typical cooling methods, heat transfer process, Personal Digital Assistant (PDA), designed temperature specifications

\section{INTRODUCTION}

A computer, which is widely used in the world, is a programmable machine that receives inputs, stores and manipulates data and provides output in a useful format. In recent years, the power density of microchip has been increasing along with the rapid development in electronic and computer technology. As high performing electronics systems become available, power consumption of the system's components such as processors, hard disk and main board, continues to increase. If suitable protection is not available, components can fail due to operation outside their designed temperature specifications.

Thermal sensors are installed in certain computer parts along with internal logic that shuts down the computer if reasonable bounds are exceeded. It is unwise to rely on such preventative measures and may not prevent repeated incidents from permanently damaging the electronics components. Therefore, cooling of electronic systems is essential in controlling the component temperature and avoiding any hot spot. Electronic cooling methods are commonly adopted together with different technologies to enhance the heat transfer process.

Electronics cooling is the process of transferring heat from components. Because a computer system's components produce large amount of heat during the operation, this heat has to be dissipated in order to keep these components within their safe operating temperature range. The electronics components are certainly sensitive to performance loss and damage. Overheated parts generally exhibit a shorter maximum life-span and may give isolated problems resulting in system down. To maintain the function of a computer, various cooling methods are used to achieve greater processor performance or to reduce the noise pollution caused by typical cooling methods.

Classification in electronics cooling: There are several methods to cool down the electronics components, for example, the pin-fin heat sink, confined jet impingement, heat pipe and so on. The cooling techniques can be classified as active and passive methods. The passive schemes do not need any external power such as fans or blowers. On the other hand, active schemes require external power to dissipate the heat from the electronic devices.

Heat sink in electronic cooling: In general, heat sinks are designed to take advantage of extended surfaces for example plate fins or pin fins. Jet impingement can also be incorporated into the design to further enhance the heat transfer. Because the space available is limited and the low power consumption is desired, the heat sink performance becomes the focus of many studies.

There are several ways to improve cooling rate in heat sinks, for example, heat sinks should be designed to have a large surface area since heat transfer takes place at the surface. In addition, flatness of the contact surface is very important because a nominally flat contact area reduces the thermal resistance between the heat sink and heat source. 
Am. J. Applied Sci., 9 (3): 436-439, 2012

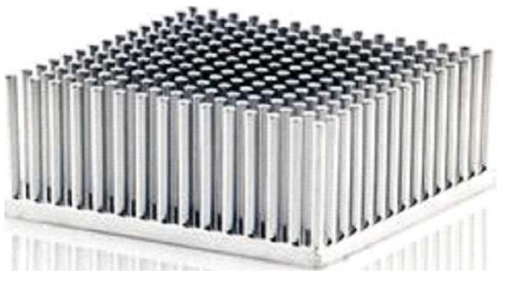

Fig. 1: Circular Pin-Fin Heat Sink

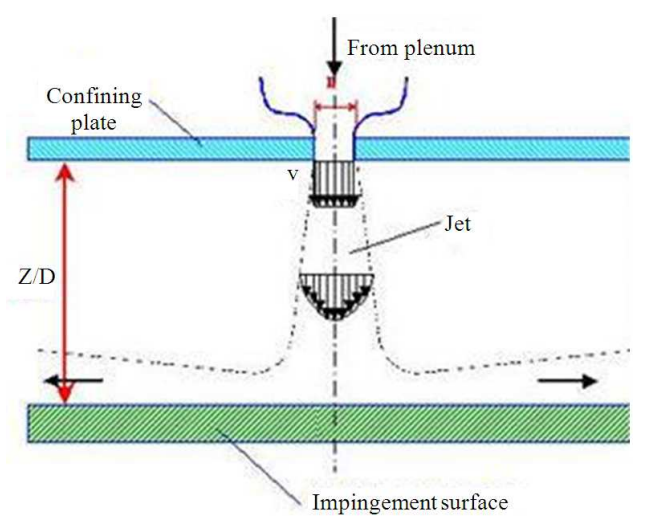

Fig. 2: Confined Jet Impingement

Heat sinks have to be designed to allow the cooling fluid to reach all cooling fins and to allow good heat transfer from the heat source to the fins as well. The heat sink performance also depends on the type of fan because airflow has a direct influence on its enhancement characteristics.

Pin-Fin heat sink: Air cooling is a simple method to dissipate heat by using air as a coolant. In the electronic applications, air cooling is widespread in computers and CPU cooling because it is low-priced, effective and reliable. It works by making the object to be cooled have a larger surface area or have an increased airflow over its surface, or both.

The pin-fin heat sink is shown in Fig. 1. It is the heat sink that has multiple pins. These pins extend from the base and their cross sectional area can be cylindrical, elliptical, or square. The pin-fin arrangement is the straight fin and runs the entire length of the heat sink. The variation on the straight fin heat sink is a cross-cut heat sink. The pitch of pin-fin is finer than regular heat sink.

Energy dissipated by electronics component is transferred to the heat sink by conduction and from heat sink to the ambient air by natural or forced convection, depending on the power dissipation requirement.

In theory, the bigger surface area, the more heat transfer can be. However, this is not always true.
Table 1 Performance of Fins with Different Fin Shapes (Li, 2008)

\begin{tabular}{lccl}
\hline Heat transfer area & Regular fins & Elliptic fins & Ratio \\
\hline (Fin and base) $\left(\mathrm{m}^{2}\right)$ & 0.00040 & 0.000361 & 1.11 \\
Total weight $(\mathrm{kg})$ & 0.00136 & 0.001184 & 1.15 \\
Total heat rate $(\mathrm{W})$ & 2.1170 & 1.511000 & 1.40 \\
Pressure loss (Pascal) & 490.0000 & 355.000000 & 1.38 \\
\hline
\end{tabular}

Table 2: Performance of Rectangular Fin with Different Fin Thickness (Li, 2008)

\begin{tabular}{llr}
\hline & & Rectangular fins \\
\hline $\mathrm{b}=2 \mathrm{~mm}$ & $\mathrm{q}(\mathrm{W})$ & 2.117 \\
$\mathrm{~b}=1 \mathrm{~mm}$ & $\Delta \mathrm{P}(\mathrm{Pa})$ & 490.000 \\
& $\mathrm{q}(\mathrm{W})$ & 2.350 \\
& $\Delta \mathrm{P}(\mathrm{Pa})$ & 606.300 \\
\hline
\end{tabular}

The total heat transfer depends on surface area as well as the temperature gradient. In fact, the concept of a pin-fin heat sink tries to pack as much surface area into a given volume as possible (Kordyban, 1998).

Jet impingement cooling: Another electronics cooling technique is jet impingement cooling as shown in Fig. 2. Because some applications require high convective heat transfer rate, the jet impingement can be selected. The coolant is forced through a small orifice to form a jet and the jet is directed toward the surface of the electronics devices. The jet impingement may effectively remove large heat fluxes. Moreover, the system can be operated at lower pressure in comparison to the other methods and the heat transfer performance can be further increased using two-phase flow cooling and by hybrid system between finned heat sink and jet impingement cooling (Brignoni and Garimella, 1999).

The impingement jet on fins with different shapes in the heat sink was numerically investigated. The performance results were shown in Table 1 and 2. The results showed that the performances of fin are affected largely by the fin shapes. For longer fins or fin with smaller fin thickness (b), the shape effect on the heat transfer became relatively less important than on pressure drop (Li, 2008).

Heat pipe for electronics cooling: Next cooling technique is heat pipes as shown in Fig. 3 that has been commercially available since the mid 1960's. Heat transfer mechanism in heat pipe combines the principles of both thermal conductivity and phase transition to efficiently manage the transfer of heat between two solid interfaces.

In the past few years, the electronics industry has claimed that heat pipes are reliable and cost-effective solutions for high-end cooling applications. This method is still relatively expensive. The heat pipe can effectively be used when space is tight such as in small form-factor PC and laptop. 


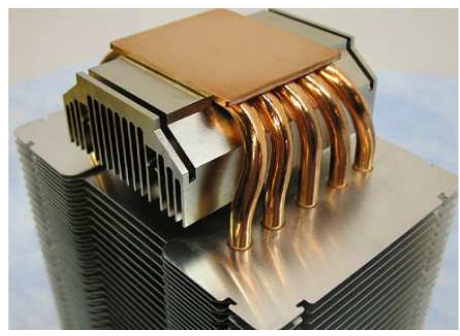

Fig. 3: Heat Pipes Cooler with Aluminum Fins

Table 3: Pulsating Heat Pipe Test Results (Zuo et al., 2000)

\begin{tabular}{llll}
\hline Mechanism & $\begin{array}{l}\text { Heat pipe } \\
\text { descriptions }\end{array}$ & Maximum q" & $\begin{array}{l}\text { Thermal } \\
\text { resistance }\end{array}$ \\
\hline Conduction & Cu Block (\%) & $150 \mathrm{~W} / \mathrm{cm}^{2}$ & $0.933^{\circ} \mathrm{C} / \mathrm{W}$ \\
Pulsating & 60 fill ratio & $175 \mathrm{~W} / \mathrm{cm}^{2}$ & $0.27^{\circ} \mathrm{C} / \mathrm{W}$ \\
Pulsating & 40 fill ratio & $175 \mathrm{~W} / \mathrm{cm}^{2}$ & $0.58^{\circ} \mathrm{C} / \mathrm{W}$ \\
Pulsating & 50 fill ratio & $160 \mathrm{~W} / \mathrm{cm}^{2}$ & $0.60^{\circ} \mathrm{C} / \mathrm{W}$ \\
Pulsating & 55 fill ratio & $175 \mathrm{~W} / \mathrm{cm}^{2}$ & $0.30^{\circ} \mathrm{C} / \mathrm{W}$ \\
Pulsating & 60 fill ratio & $175 \mathrm{~W} / \mathrm{cm}^{2}$ & $0.27^{\circ} \mathrm{C} / \mathrm{W}$ \\
Pulsating & 70 fill ratio & $220 \mathrm{~W} / \mathrm{cm}^{2}$ & $0.16^{\circ} \mathrm{C} / \mathrm{W}$ \\
Pulsating & 80 fill ratio & $185 \mathrm{~W} / \mathrm{cm}^{2}$ & $0.20^{\circ} \mathrm{C} / \mathrm{W}$ \\
\hline
\end{tabular}

Nowadays, the heat pipe becomes popular because its advantages as listed above. Many techniques are used to increase the heat transfer in heat pipe, for instance, the pulsating technique. The pulsating heat pipe is the one of effective method. The working fluid inside heat pipe is oscillated by external power. Zou et al. (2001) numerically studied pulsating heat pipe. The result of performances was listed in Table 3 and it clearly showed that pulsating heat pipe with appropriate fluid fill ratio dissipated heat over $200 \mathrm{w} \mathrm{cm}^{-2}$. By the way, the heat flux of $150 \mathrm{w}$ $\mathrm{cm}^{-2}$ would be dissipated from the pure copper heat pipe. Also, the thermal resistance of pulsating heat pipes with different fill ratio was obviously lower than original pure copper pipe.

Moreover, experimentally investigated the closeend oscillating heat pipe. The R-141b with filling ratio of $50 \%$ by volume was used to be working fluid and inclination angles of $0,20,40,60,80$ and 90 degree from horizontal plane for heat pipe were studies. Finally the correlation of the close-end oscillating heat pipe was presented.

Micro scale heat sink: In order to improve micro scale technologies for electrical applications, various kind of electronic products are reduced in size to meet the specifications for portable design. For instance, laptop, Personal Digital Assistant (PDA) and smart phone attain the light weight and compact size required for movability. Nevertheless, owing to the micro scale electronic products, dissipated heat from micro scale electronic components become the serious issue.

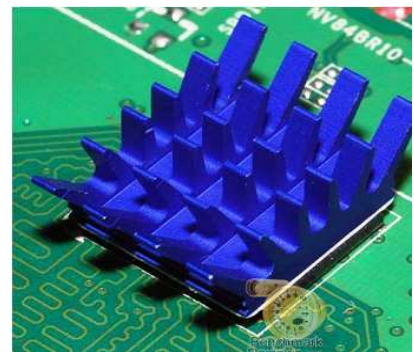

Fig. 4: Micro Rectangular Heat Sinks on the Motherboard (Normann, 2011)

Many cooling methods are adopted for the electronics component. Micro heat sinks as shown in Fig. 4 are one method that is receiving considerable attention. The average length, width and height of heat sink are generally less than $2,000,2,000 \times 2,000 \mu \mathrm{m}$. They provide greatly enhanced convective heat transfer rate and would be able to meet the demands of the cooling challenges for the microprocessors for many generations to come. Because of undeniable advantages of smaller physical dimensions and higher heat transfer efficiency, the study of micro-channel flows has become an attractive research topic with a fast growing number of researches (Pan et al., 2008).

Vibration technique: Flow over bluff body is important in many engineering applications. Most researchers focus on the flow over cylinder and square. For the flow past the cylinder, the vortices are shed with natural frequency and vortex shedding can be controlled by oscillation of cylinder. It is referred to a vortex resonance phenomenon. This phenomenon is used to enhance wake to increase the heat transfer in electronics devices, fuel cell, heat exchanger and so on. The useful frequency which is used to enhanced heat transfer is generally below $1,000 \mathrm{~Hz}$ (Rohsenow et al., 1998).

The vibration technique was adopted by Gururatana (2011) for small scale pin-fin heat sink and the numerical study was also made. The results of maximum heat transfer rate and Maximum pressuredrop for square pin fin with vibration in $\mathrm{x}$ direction (streamwise direction) were illustrated in Fig. 5 and 6 , respectively. It was observed that the vibrating heat sinks with appropriate frequency clearly increased heat transfer rate. However, the pressuredrop increased with frequency as well. In order to justify the suitable frequency, the heat transfer enhancement performance as shown in Fig. 7 was used to consider. It was found that heat transfer enhancement performance for two dimensional small scale pin-fin heat sinks increases until certain frequency; later it rapidly decreases with frequency. 


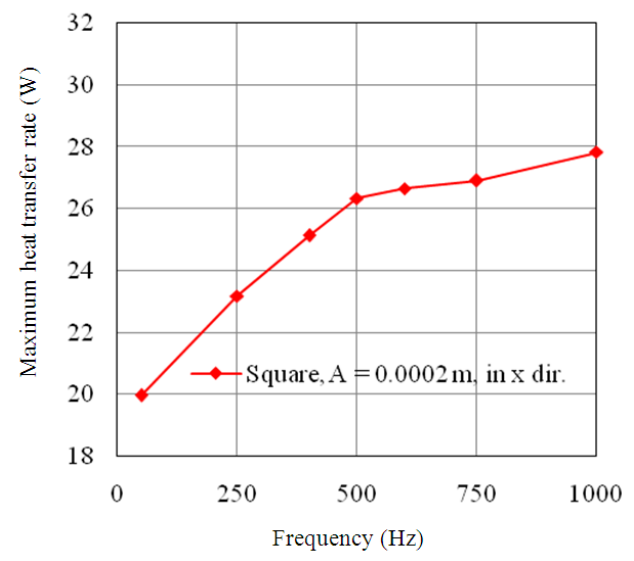

Fig. 5: Effect of Frequency on Maximum Heat Transfer for 2D Square Pin Fin (Gururatana, 2011)

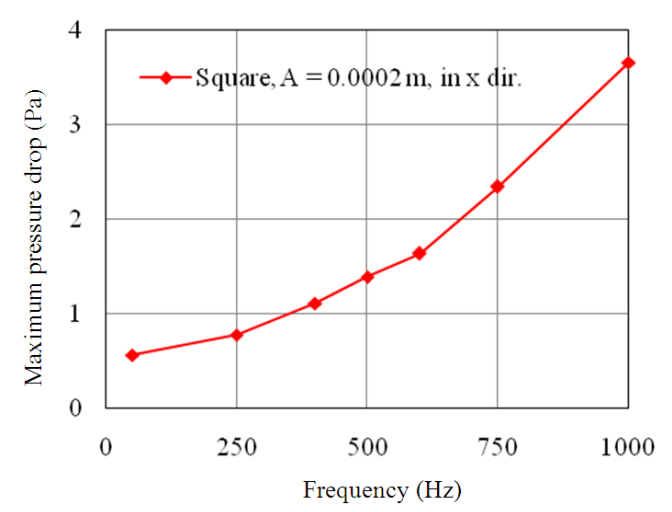

Fig. 6: Effect of Frequency on Maximum Pressure Drop for 2D Square Pin Fin (Gururatana, 2011)

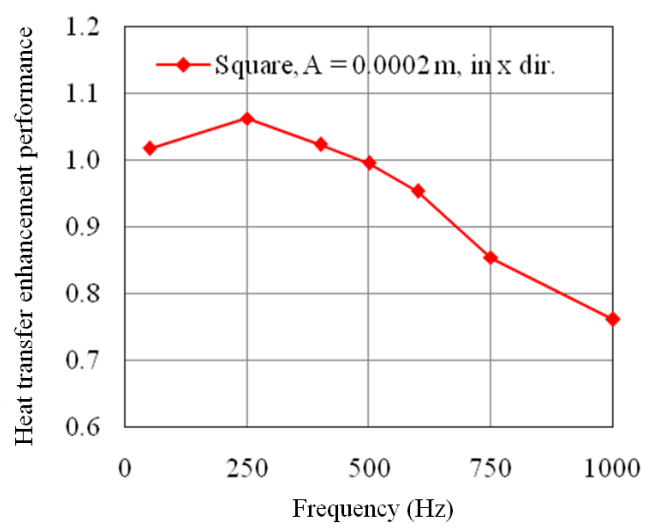

Fig. 7: Effect of Frequency on Heat Transfer Enhancement Performance for 2D Square Pin Fin (Gururatana, 2011)

\section{CONCLUSION}

Various types of heat transfer enhancement techniques are presented. The different cooling methods, active and passive, are adopted to use for electronics cooling. The useful cooling methods can increase heat transfer rate. Nevertheless, the pressuredrop would obviously rises, when heat transfer rate is enhanced. In order to avoid excessive cost due to high pressuredrop, justification and optimization is needed to obtain optimum cost and cooling rate.

\section{ACKNOWLEDGEMENT}

This study is achieved with the supports from the Faculty of Engineering at Si Racha, Kasetsart University $\mathrm{Si}$ Racha campus. Author appreciates Associate Professor Dr. Xianchang Li from Lamar University, Beaumont, TX, USA for his support and advice.

\section{REFERENCES}

Brignoni, L.A. and S.V. Garimella, 1999. Experimental optimization of confined air jet impingement on a pin fin heat sink. IEEE Tran. Components Packag., 22: 399-404. DOI: 10.1109/6144.796542

Gururatana, S., 2011. Heat transfer enhancement of small scale heat sinks for electronics cooling. Ph.D. Thesis, Department of Mechanical Engineering College of Engineering Lamar University.

Kordyban, T., 1998. Hot Air Rises And Heat Sinks: Everything you Know About Cooling Electronics is Wrong. 1st Edn., ASME Press, New York, ISBN-10: $0791800741 \mathrm{pp:} 223$.

Li, X.C., 2008. Conjugate heat transfer of jet impingement on short fins with different shapes. Proceedings of the 11th Intersociety Conference for Thermal and Thermomechanical Phenomena in Electronic Systems, May 28-31, IEEE Xplore Press, Orlando, pp: 49-56. DOI: 10.1109/ITHERM.2008.4544253

Pan, C., P.C. Li, C.T. Lu and K.C. Lin, 2008. MicroChannel heat sink. US Patent, US.

Rohsenow, W.M., J.P. Hartnett and Y.I. Cho, 1998. Handbook of Heat Transfer. 3rd Edn., McGrawHill, New York, ISBN-10: 0070535558 pp: 1344.

Zuo, Z.J., M.T. North and K.L. Wert, 2000. High heat flux heat pipe mechanism for cooling of electronics. Proceedings of the 7th Thermal and Thermomechanical Phenomena in Electronic Systems, May 23-26, IEEE Xplore Press, Las Vegas, NV, USA., pp: 122-128. DOI: 10.1109/ITHERM.2000.866180 